The Geneva Papers on Risk and Insurance, 22 (No. 84, July 1997) 368-377

\title{
The Netherlands Recover from their Illness
}

\author{
by A. C. Blom*
}

\section{Introduction}

\subsection{The Netherlands recover}

The Netherlands recover from their illness. Are the Dutch less healthy than the Belgians, Germans, Japanese or Americans? No, there are no indications of this. "The Netherlands are sick", refers to the unhealthy situation in the country. Too many Dutch frequently rely on the country's social sickness and disability schemes for too long. The costs resulting from this behaviour have a paralysing effect on Dutch society in general and the business community in particular. Fortunately, they are in recovery. Since 1993, absenteeism and disability figures have decreased substantially. Nevetheless, it took a radical operation to achieve this, and the therapy is not entirely completed.

\subsection{Outline}

The following is an outline of the symptoms the Netherlands are incurring. Specifically, which have unveiled the unhealthy situation and the necessity for intervention and what treatment is available. What are the possibilities and restrictions of the treatment. And, finally, some advice for the future.

The main points discussed shall be: the financial and economical aspect of the matter and the special role insurers play in the battle against high costs resulting from absenteeism and disability.

\section{The symptoms}

\subsection{High labour costs}

The Dutch are famous for their trade and thriftiness (or in friendlier terms: cost awareness). The problem of high absenteeism and disability rates manifests itself in precisely these two areas: because the costs have been allowed to rise for too long, the country is well on its way to losing business to countries with a more economical social security scheme. Globalisation and regionalisation make the competition between countries increasingly

\footnotetext{
* UAP-NieuwRotterdam Verzekeringen B.V.
} 
difficult. In this highly competitive battle, the Dutch economy has difficulty trying to maintain its position. For example: labour costs for the assembly of a Fokker aeroplane are $35 \%$ higher than those of a competitor (Aerospace). This fact has undoubtedly influenced the downfall of this company. Akzo Nobel will relocate part of its fibre division in Poland, Philips moves one of its important head offices to the Far East, KLM will start flying with Indian stewardesses.

These are just a few of the headlines found in the Dutch newspapers about companies relocating their production facilities to countries with lower labour costs. Not only to Asia or Eastern Europe, but also countries like the U.K. and Ireland.

Figure 1: Average hourly wages in industry in BFR (1991)

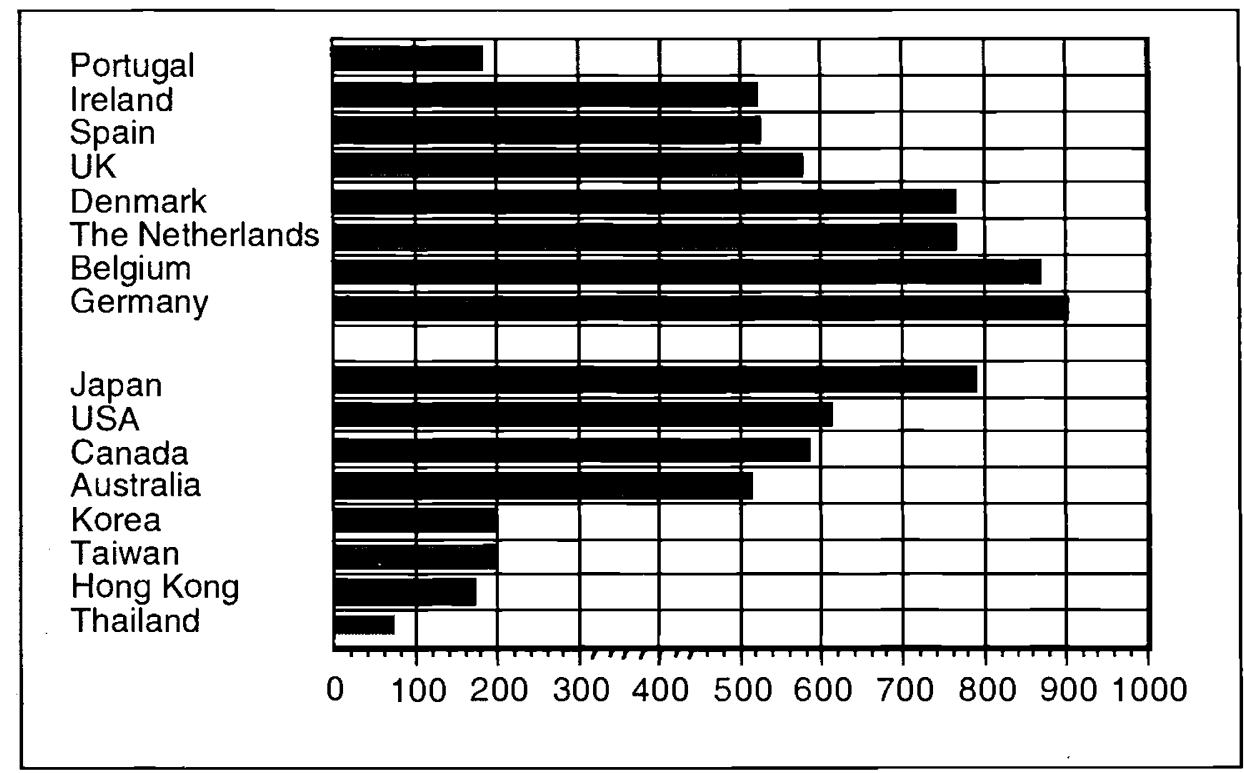

Source: Eurostat, Labour Cost Updating 1989-1992; Institut des Deutschen Wirtschaft; free adaptation: KPMG Bureau voor Economische Argumentatie.

\subsection{High social benefit costs}

Fundamentally, high labour costs interfere with the competitiveness of the Netherlands. In view of the EMU, these costs will have to be brought more in line with their European neighbours. The problems are mainly caused by the so-called wedge. Namely, the difference between gross and net salaries, caused by social premiums and taxes. The diagram below shows that more than $40 \%$ of the gross salary of a single person is spent on the above mentioned. In countries such as France, Italy and the U.K., this difference is about $25 \%$ lower. 
Figure 2: Social insurance expenditures as percentage of GDP (1993)

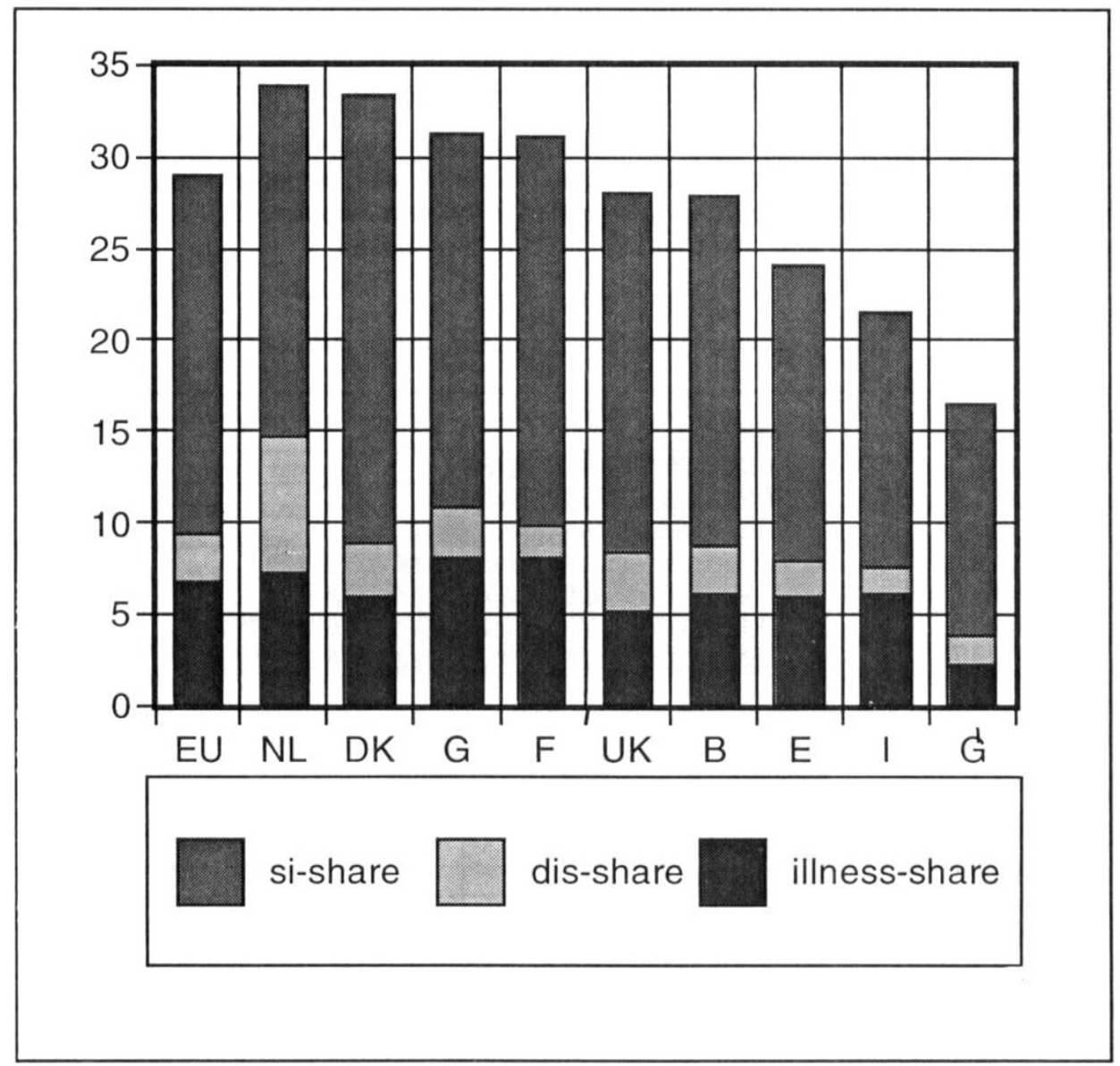

Source: Social Memorandum 1996, Dutch Ministry of Social Affairs and Employment; adaptation: KPMG Bureau voor Economische Argumentatie.

\subsection{The wedge}

The problem of high wedges is mainly due to very high expenses caused by the Dutch social security system. In 1994, expenditures amounted to some 130 billion Dutch guilders, of which 34.3 billion (more than a quarter) was spent on sickness and disability benefits. Comparing these figures to those in other European countries, it can be concluded that the above is a main cause of high labour costs in the Netherlands. The cost of both sickness and disability benefits, being approximately $15 \%$ of the GNP, are one third to $50 \%$ higher than in neighbouring countries. 
Figure 3: The wedge: taxes and premiums as percentage of gross income

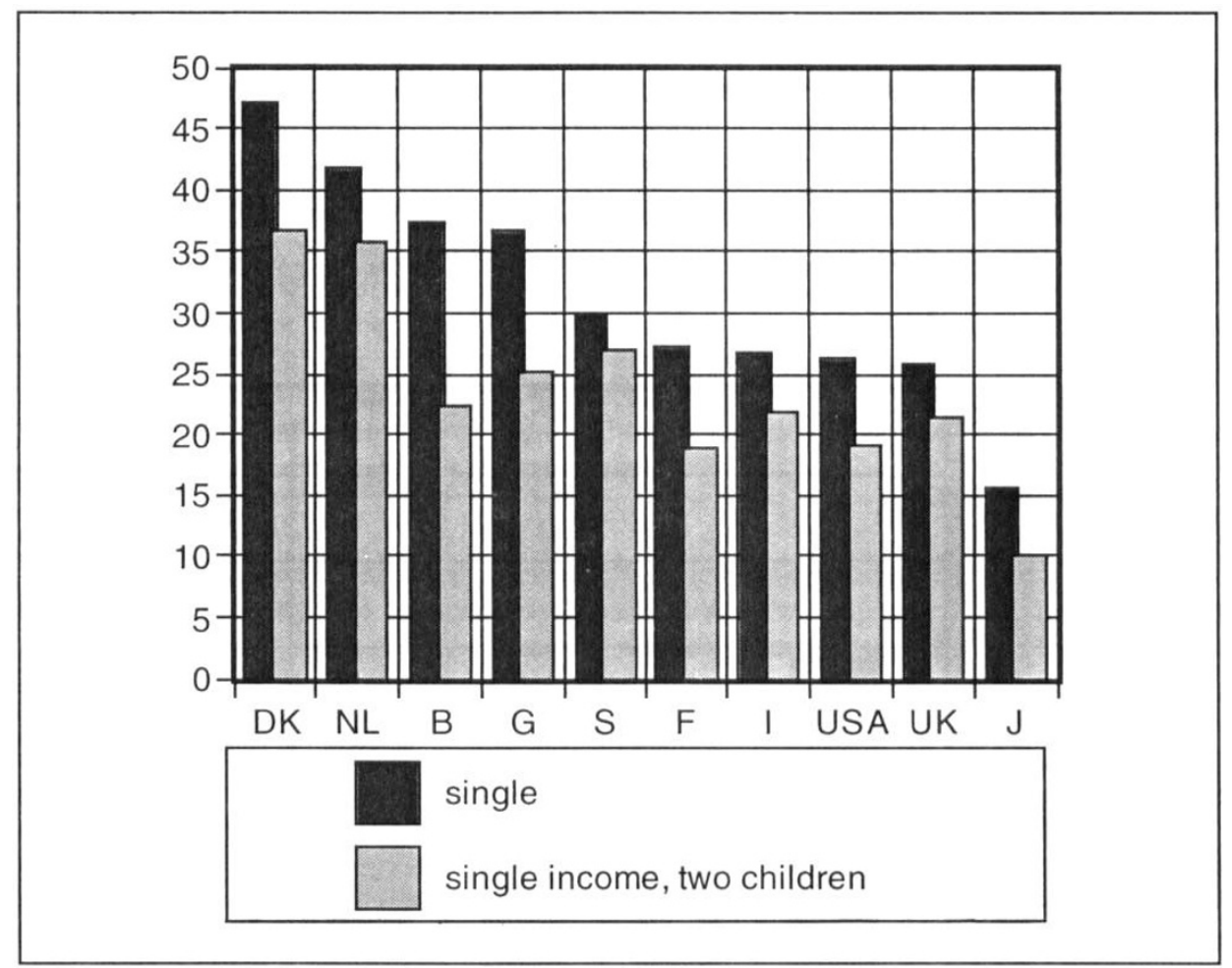

Source: OESO (1994), adapted by KPMG Bureau voor Economische Argumentatie.

\subsection{High expenditures for the individual employer}

It is incorrect to assume that total macro-costs of sickness and disability benefits include costs that employers pay. The major part of the costs for employers from work absences due to illness are not caused by premiums to be paid, but by loss of production, costs for employee replacements and costs rising from hours compensated by other employees. According to research on the subject, 50 to $70 \%$ of the total costs involving absenteeism are the result of the latter. The costs for adapting the work station, benefits in addition to sickness benefit, ARBO services etc. are also important. It is therefore not exaggerated to estimate that the total direct and indirect costs for employers are approximately 45 billion guilders, or $19 \%$ of GNP. 


\section{The diagnosis}

\subsection{Absentees and disability}

The realisation that the Netherlands are sick has had such an impact that an inquiry division was established by parliament to determine a diagnosis. In the Netherlands, this committee represents the highest competence that parliament could implement to investigate a matter which has become uncontrollable. The investigation has proven that high sickness benefit costs have not been caused by the generous regulations in the Netherlands.

Figure 4:Percentage absenteeism and disability in six European countries (1990)

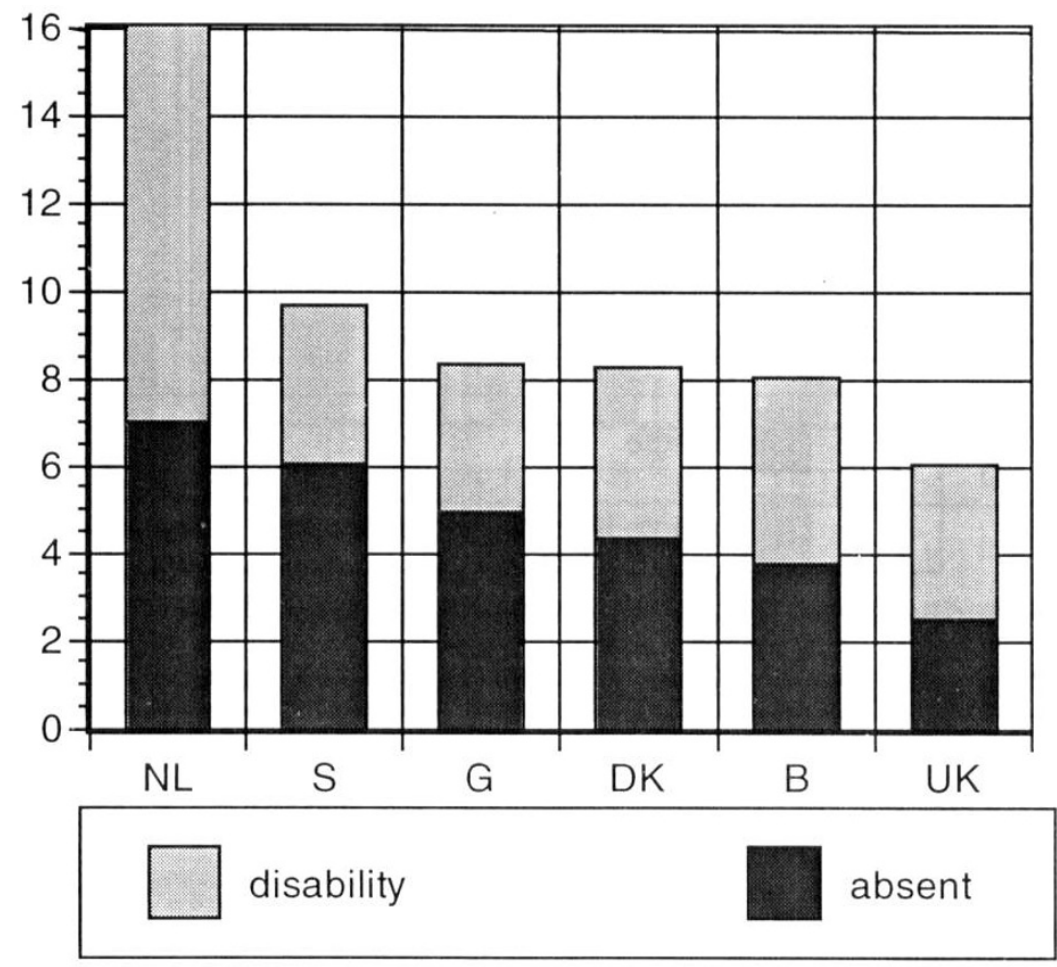

Source: Einerhand et al. (1996); adaptation: KPMG Bureau voor Economische Argumentatie.

Figure 4 clearly depicts the location of the problem: both the absenteeism and, most of all, the disability rate are far higher than in other European countries. A comparison between the Netherlands and Belgium show the following: in the Netherlands, about $9 \%$ of the working population is unable to work due to disability, compared to $4 \%$ in Belgium; 26 days of absence in the Netherlands, compared to 14 in Belgium. Absenteeism and disability in the United States and Japan amount to only $1.5 \%$ in each country. 
Why does the problem of absenteeism and disability have such a grip on the working population of the Netherlands? There are several explanations. The central issues is that employers, employees and social security institutions have no direct (financial) interest in a lower percentage of absenteeism, nor a lower figure of unemployment due to disability.

\subsection{Lack of incentives}

\subsubsection{The employer}

Each company pays the same premium, regardless of high or low absenteeism figures within the company. The sickness benefit practically always begins on the first day of absence; contrary to neighbouring countries, the employer runs no risk. Consequently, the employer is unaware of the rise and fall of absentee and disability figures within the company. A company showing a higher than average rate of absenteeism even shows profits. After all, the illness benefit the employer receives exceeds the premium he must pay. Due to a lack of financial incentives to reduce absenteeism and incapacity rates, the policy on these matters has been neglected in many cases.

\subsubsection{The employee}

This practically non-existing absenteeism-policy makes things easy for employees to report in sick, partly due to insufficient possibilities for employers to take disciplinary actions. The employer has no right to ask for a medical certificate, affirming the employee's incapacity to work. In addition, the high level of protection against dismissal in favour of the employee, especially while ill, plays a role in this matter. Employees are also not financially disadvantaged when ill, and the disability settlement is an attractive alternative for early retirement. Compared to abroad, sickness and disability benefits in the Netherlands are very high and stipulations for collection are very broad. The employee is not confronted with waiting periods, as in many other countries either. All this amounts to a very low threshold to report ill or make use of the disability scheme.

\subsubsection{Social security institutions}

Even public institutions, charged with offering insurance against sickness and disability have no particular interest in reducing the rates. Public execution is not aimed at getting employees back to work as soon as possible. The accent lies on executing payments and equality of rights. Both insurance coverage and case-settlement can be marked down as sameness. Everyone is treated equally. No special attention is given to individuals. The public character and the monopoly position of executive institutions are to blame. In addition, execution is hindered by a strict separation between the treating and controlling medics in the Netherlands. Besides, the Netherlands have a long waiting list for health care. These two matters hinder a speedy return to work.

One can only conclude that the social security system has proven inefficient in controlling the volume of absenteeism and disability and the expenses that arise from it. As we have seen, this outcome places a heavy burden on the economic strength of the Netherlands. 


\section{The remedy - decreasing-policy and reintegration of absentees}

\subsection{Market incentives}

Employers obtain a financial interest in reducing the high rate of absenteeism and disability. First of all, in 1994, a risk period of six weeks was established in the sickness benefit scheme. During this six week period, the employer is obliged to pay the salary of the incapacitated employee himself. Private insurers developed alternatives for employers who do not want to carry the risk themselves. Secondly, the public health benefit insurance was abolished. Instead, employers are now obligated to pay $70 \%$ of the salary of the absent employee for one year. Whether they wish to privately insure themselves against absenteeism is up to the employer himself. Finally, a bill has been proposed, offering employers the possibility to either carry the risk of the first five years for the incapacitated employee, or to insure themselves against this risk in advance.

The incentives are not only aimed at employers, but also at employees. In future, employees could be confronted with a stricter control for their absence, as the employer will have been given this responsibility. He can decide who will investigate sick employees as well as when it should be done. In addition, the amount of disability benefits will be reduced. The benefit, presently $70 \%$ of the last earned salary will drop to a substantially lower level within a few years. Many have compensated for this "gap" with private insurance.

The criteria for application to obtain a disability benefit have been harshly accentuated. All disabled employees are being re-examined according to very strict regulations. Subsequently, many have lost their benefits. Due to the privatisation of the sickness benefit scheme and the upcoming private Arbo-institutions, the execution of the matters under view has been commercialised. Private insurers and medical centres have a financial interest in the reduction of absenteeism and disability. This offers perspectives for a more efficient execution, more tailor-made solutions, investment in preventive measures and reintegration-activities. In addition, a trend to increasingly commercialise public insurance has emerged.

\subsection{Results after just one year}

All these recently taken measures have already produced remarkable results. One year after the introductions of the own-risk period of 6 weeks for the sickness benefit scheme, absenteeism has dropped by an average of $18.5 \%$. One year after the implementation measures regarding disability benefits, the incoming stream of cases has decreased by $21 \%$ and the outgoing number has increased by the same rate. These developments have caused a turn in the total number of people who receive sickness or disability benefits.

\subsection{Volume of years of benefit payments}

The effects caused by the privatisation of the sickness benefit scheme are not yet visible. The proposal of commercialisation of the disability scheme has come into force January $1,1997$.

\section{Possibilities and limitations}

\subsection{Common factor}

The remedy basically comes down to a re-verification of responsibilities. The "Leitmotif", or common factor, in the design of financial incentives is the withdraw of the government. The government is diminishing the execution of some of its fundamental tasks, 
distancing itself from parts of the social security system and giving back responsibilities to civilians. Wherever the government privatises social insurance, commercial opportunities for private insurance arise. This insurance is utilised in addition to the public social system. As already mentioned, the insurance compensats for the gap, which is now arising in disability benefits: the so-called national disability insurance gap. In addition, the sickness benefit offers the following: first, coverage for the own-risk period of six weeks and, only just recently developed, for a complete year of absence. The government does, however, stipulate certain conditions for the privatisation of social insurance. These conditions refer to the accessibility to private insurance and their affordability. The position of the chronically ill and small entrepreneurs will be examined in more detail. For the insurance business, this entire market offers both major opportunities as well as significant dangers.

\subsection{Risks and limitations}

The risk is that the expectations one has from the government will, without a doubt, be projected onto private insurers. Private insurers, however, operated in a competitive market and, for social insurance, set other conditions than the government. One must realise that the social insurer operates from a monopolistic position. From that position, the government can stipulate an obligation for all citizens to insure themselves. This guarantees an increase in insured with both high and low risks. It is, therefore, simple for the government to proclaim that everyone has access to this insurance. The government can enforce solidarity among the insured. The insured most often pays a premium which has little to do with his own risk.

Private insurers, on the other hand, are not in a position to function that way. Private based on voluntariness, not obligation. The insurance premiums correspond to the extent of each persons risk. A house with a straw roof would incur a higher fire insurance premium than a normal roof. A motor insurance is more expensive in Amsterdam, where the risk of calamity is much higher than in the quiet region of the rural southern part of the country. Finally, someone of weaker health pays a higher premium for disability insurance. Consequently, the anti-selection phenomenon arises. People who know that they run a high risk will seek to insure themselves much earlier than others. Private insurers must, therefore, be given the opportunity to assess the risks in order to be able to determine the correct premium. In the case of disability insurance, this assessment is derived at by medical examinations. If insurers would not have these examinations, they would obtain premiums which would be too low to compensate for benefits, which would eventually result in bankruptcy.

These are the limiting conditions insurers must establish, regarding insuring social risks. This, for example, means that the insurance market cannot offer solutions on an individual basis for people with a higher health risk. It is the government that must take on the responsibility.

\subsection{Challenges and possibilities}

The challenge is to insure social risks in a way that is affordable and accessible. This within the framework of a micro-economical conduct of business and private insurance technique. Insurers are prepared to investigate where the outer limits of private insurance lie, but they can never completely take over the task of the social insurer. Three starting-points are the basis for the transitional stage from a public to private aspect of sickness and disability insurance: 
1) The accent lies on a company's insurance. All employees are to be insured within the same contract.

2) Only for collective insurance do insurance companies offer complete accessibility to start with. Even chronically ill employees will be accepted. Employees with normal health also partly pay for the premium of their colleagues with an increased health risk. Subsequently, a "solidarity within the own community" is created.

3) This accessibility to collective insurance is related to a socially acceptable maximum premium. For smaller companies, an extra safeguard against substantial premium increases will be incorporated.

\subsection{The market effect}

What effect does private insurance have and how does it contribute to the reduction of absenteeism and disability rates? The following are three important points:

1) The insurance premium is not equal for each employer, but depends on the evolution of absenteeism and disability within the company. If the employer succeeds in reducing the rate of absenteeism and disability within his company, he will be rewarded with a lower insurance premium. Higher rates imply a rise in premiums. This way, the employer is motivated to invest in a proper absenteeism reduction policy and adequate working conditions. The Arbo-companies assist employers in achieving this goal.

2) Insurers also have an interest in reducing absenteeism and disability. First, it strengthens their competitiveness, and secondly, insurers gain from the reintegration of a disabled employee. Private insurers must reserve funds for possible future benefits for disabled employees. This is called funding. It is attractive for insurers to invest money in rehabilitation or an adapted working situation in order to allow disabled employees to return to work. This investment is easily retrieved by the insurer because the reserved money is released for profit. Social insurers do not have such a financial stimulus. They work according to the apportionment method and do not aim for profit.

3) Competition compensates for high premiums. In order to distinguish himself from his competitor, an insurer will present "tailor-made" proposals. Health benefit insurance is available in many forms. An employer can choose an own-risk or not. If he chooses an own risk, it can be in the form of a period or an amount of money. For the latter, the insurer only settles the payment if the health benefit exceeds the agreed limit. Predictable absenteeism is therefore paid by the employer. Each employer will choose the insurance that suits his situation best. With the so-called employee-benefit insurance, employers can combine sickness benefits, disability and health care insurance all in one. Therefore, they do not only obtain premium discounts, but possibly also advantages for case treatments. Deals that insurers make with hospitals and rehabilitation centres in relation to health care can be advantageous for the speedy recovery of an employee. Consequently, absenteeism decreases, the employee recovers much quicker and the insurer pays less sickness benefits.

\section{A healthy future}

In his book "Capitalism Contra Capitalism", the former director of the French Planning Bureau, Michel Albert, concludes that capitalism in the Rhine area is superior to Anglo-Saxon capitalism, with the exception of one subject: employment due to the wedge. 
The wedge mostly pays for the welfare state, but also renders labour very expensive. The Netherlands are among those countries with the largest wedge and the highest labour costs. This is largely due to the exorbitantly high costs brought about by absenteeism and disability. These costs undermine the Netherlands' competitive position and form. Considering globalisation and the unification of Europe, this is a danger for employment. These are the symptoms that have awakened the Netherlands, leading to the statement by ex-prime minister Ruud Lubbers: "The Netherlands are sick".

The Netherlands are well on their way to becoming a healthy country. Privatisation of social schemes is a remedy. It motivates employers, employees and insurers financially to battle absenteeism and disability rates. Insurers contribute by offering socially and microeconomically reliable insurance. Not only because of the social responsibility which the insurance industry carries, but also for its own interests: growing, making a profit and creating employment. Healthy Netherlands offer a perspective for the competitiveness of the business community and employment, both at present and in the future.

Nevertheless, it has not completely been accomplished yet. As mentioned, a bill is being considered to further privatise the disability scheme. Another problem to tackle is the long waiting list for health care. Insurers can play a role in solving this problem by offering employee benefit schemes. However, some may fear a dichotomy in society if sick employees are given access to treatment outside regular health care procedures. There is an ongoing heated public debate on this subject. Finally, the strict division between the controlling and treating medics is an obstruction to a speedy resumption of work. This is typically a Dutch problem, which has not been highlighted enough and deserves to be dealt with. 